\title{
The activation of semantic memory: Effects of prime exposure, prime-target relationship, and task demands
}

\author{
Steve Bueno \\ Université de Paris 13, Villetaneuse, France \\ AND \\ Cheryl Frenck-Mestre \\ CNRS and Université de Provence, Aix-en-Provence, France
}

\begin{abstract}
Priming facilitation was examined under conditions of brief incremental prime exposures $(28,43,71$, and $199 \mathrm{msec}$ ) under masked conditions for two types of lexical relationships (associative-semantic pairs, such as "wolf-fox," and semantic-feature pairs, such as "whale-dolphin") and in two tasks (primed lexical decision and semantic categorization). The results of eight experiments revealed, first, that priming elicits faster response times for semantic-feature pairs. The associative-semantic pairs produced priming only at the longer prime exposures. Second, priming was observed earlier for semantic categorization than for the lexical decision task, in which priming was observed only at the longer stimulus onset asynchronies. Finally, our results allowed us to discredit the congruency hypothesis, according to which priming is due to a common categorical response for the prime and target words. The implications of these results for current theories of semantic priming are discussed.
\end{abstract}

The initial demonstration by Meyer, Schvaneveldt, and Ruddy $(1972,1974)$ that the identification of a word is accelerated by the prior processing of a word semantically or associatively related to it has since been the topic of numerous studies. One long-debated question concerns the amount of actual semantic processing that is involved in priming. This issue involves both the type of relationship that produces priming and the type of task best-suited to test for semantic processing (for reviews, see Forster, 2004; Hutchison, 2003; Lucas, 2000; McRae \& Boisvert, 1998). The present series of experiments provides insight concerning both of these subjects.

\section{The Role of Semantics in Priming}

The role played by semantics in the facilitation observed in word-priming experiments has been addressed by Lund and Burgess (1996) in their hyperspace analogue to language (HAL) model, which has been proposed as a means of modeling semantic memory (but see Glenberg \& Robertson, 2000, and the rejoinder by Burgess, 2000). The approach taken in HAL is similar to that developed by Landauer and Dumais (1997) in their latent semantic analysis (LSA) model. Both HAL and LSA assume, as stated by Landauer and Dumais (p. 215), that "the psychological similarity between any two words is reflected in the way they co-occur in . . . language." LSA was proposed as a model of textual representation, whereas HAL has been used primarily to model word priming. However, both models represent the meaning of words as vectors in a high-dimensional space, with the vectors themselves comprising other words that co-occur (within a given window) in a corpus. In HAL, semantic meaning is captured via co-occurrence, since words that occur in similar contexts will share a high degree of vector overlap. For example, synonyms (e.g., "boat," "ship," "vessel") will have more similar vectors and will be represented as closer in meaning to each other than to associated words (e.g., "boat," "water"). These predictions have been borne out in both simulations and human response time (RT) data (Bueno \& Frenck-Mestre, 2002; Lund, Burgess, \& Audet, 1996). Concerning data from RT experiments on priming, Lund et al. (1996; Lund, Burgess, \& Atchley, 1995) suggested, in line with McRae and Boisvert (1998) and Thompson-Schill, Kurtz, and Gabrieli (1998), that previous failures to produce priming for semantically nonassociatively related word pairs can be attributed to a lack of semantic similarity, and from their own research they concluded that associative relatedness is not a prerequisite for priming facilitation (see also Hines, Czerwinski, Sawyer, \& Dwyer, 1986; Perea \& Rosa, 2002; Williams, 1996). This conclusion is further supported by the recent meta-analysis by Lucas (2000). Note, nonetheless, that the conclusion has been challenged by Hutchison (2003), who suggested, first, that Lucas's meta-analysis may have been flawed and, second, that the materials used in many of these studies in fact had higher associative values than was claimed. We shall return to these issues in the General Discussion.

S. Bueno, bueno@univ-paris13.fr 
Attempts to model semantic and associative priming have also been provided by distributed connectionist networks, such as those proposed by Cree, McRae, and McNorgan (1999); Masson (1995); McRae, de Sa, and Seidenberg (1997); and Plaut (1995; Plaut \& Booth, 2000, 2006). These models challenge the traditional view that concepts are best represented as unitary nodes within an interconnected network (see Collins \& Loftus, 1975; McKoon \& Ratcliff, 1992; McNamara, 1992; McNamara \& Altarriba, 1988; Ratcliff \& McKoon, 1988). As discussed in McRae (2004), semantic concepts are represented by sets of highly interconnected features, with these connections being derived quite simply from exposure-based (i.e., statistical) learning. That is, features (of a concept) that naturally tend to co-occur will be encoded together, leading to the learning of correlations between the features; moreover, the stronger the correlation between two features, the stronger their connection weight (McRae \& Boisvert, 1998; McRae et al., 1997). How clusters of features are correlated is also learned on the basis of co-occurrence (McRae, Cree, Westmacott, \& de Sa, 1999); the correlations are learned on the basis of positive evidence, such that the absence of a feature in a concept is generally not a part of its representation. Concepts are thus defined as learned patterns (of activation) within a multidimensional state space. ${ }^{1}$ The network settles into only one state at a given time; that is, concept recognition entails a "stable state" of the system. Semantic priming is accounted for in terms of transition time between stable states. In general, moving from one state (concept) to another - that is, resettling the network-will be faster if the two states have overlapping features rather than no overlap or prior co-occurrence (McRae, 2004; McRae et al., 1997; Plaut 1995; Plaut \& Booth, 2000). These models can also account for priming between associated words, which is attributed to learning rather than to the similarity of representational patterns. The system learns to move rapidly from a given pattern of activation to another, on the basis of context-independent co-occurrence of the two patterns (Moss, Hare, Day, \& Tyler, 1994; Plaut, 1995; Plaut \& Booth, 2000; but see Lund et al., 1995; Lund et al., 1996).

McRae and colleagues (Cree et al., 1999; McRae \& Boisvert, 1998; McRae et al., 1999; McRae et al., 1997) have provided both empirical data and simulations that clearly support the predictions of their model of semantic memory. Priming facilitation was found for category coordinates that had featural overlap and were rated as highly semantically similar but were not associatively related (according to the traditionally used forward-association norms). Moreover, greater feature overlap between category coordinates was needed to produce priming at short prime-target asynchronies (McRae \& Boisvert, 1998), presumably because of the transition time between two activation patterns, which only allowed savings to be observed at short stimulus onset asynchronies (SOAs) if the necessary change in patterns was small. Also, Cree et al. (1999) showed that category coordinate priming is not direction sensitive, which further distinguishes it from associative relatedness (but see Hines et al., 1986). Across their studies, McRae and colleagues have both stressed and demonstrated that shared category membership does not suffice to ensure semantic similarity or to produce priming. Interestingly, however, Hutchison (2003) based his opposing conclusion, that the evidence for category coordinate priming is extremely weak, on the null results of studies that did not control for the semantic (feature) overlap of prime-target coordinates (Lupker, 1984; Moss, Ostrin, Tyler, \& Marslen-Wilson, 1995; Shelton \& Martin, 1992), as well as on the premise that strategic processing could account for the obtained effects (Hines et al., 1986; Perea \& Rosa, 2002; Williams, 1996). These issues will be tested in the present experiments and revisited in the General Discussion.

To capture differences in semantic and associative priming, Plaut (1995) simulated priming results for artificially created pairs in his distributed attractor network. For associated pairs, priming was absent at short "SOAs" (updating cycles) but emerged with increasing duration of the prime, whereas the opposite result was observed for semantic pairs. This pattern follows nicely from the predictions of attractor networks (see McRae, 2004; Plaut \& Booth, 2000): For words that share semantic-feature overlap, priming facilitation should be greater when the semantic units of the prime have not yet approached asymptote (i.e., earlier in processing). Quite the contrary is true for associative pairs, for which facilitation is not due to overlap in activation patterns but to learning, during training, of the co-occurrence of these patterns. Hence, the more fully processed the prime, the more optimal will be the position to move toward the associated target. Plaut's simulations provide another attempt to distinguish between semantic and associative priming, which we pursued in the present series of experiments. In a series of eight experiments, we examined two types of prime-target relationships (semantic-feature vs. associative-semantic) and several prime-target SOAs (beginning with a 28-msec prime exposure). In addition, the effect of task demands was studied, as outlined below.

\section{The Effect of Task Demands on Priming}

Whereas many studies have examined priming for various prime-target relationships (for reviews, see Hutchison, 2003; McRae \& Boisvert, 1998; Moss et al., 1995; Williams, 1996), relatively less attention has been given to the task used. This is undoubtedly linked to the efficiency of the lexical decision task for evidencing priming (see Neely, 1991; Neely \& Kahan, 2001). Beginning with the seminal study by Balota and Chumbley (1984), however, there have been various investigations of the limitations of using a sole task, such as lexical decision, to study activation of the lexicon and, more specifically, the activation of semantic information (see also Becker, Moscovitch, Behrmann, \& Joordens, 1997; Lupker, 1984; Seidenberg, Waters, Sanders, \& Langer, 1984). Balota and Paul (1996) compared the results obtained across six experiments in which the task was naming, primed lexical decision, or a relatedness judgment. They concluded that only the relatedness judgment task induced processing at the semantic level of representation. Williams (1996) compared naming with lexical decision and concluded much the same - that is, that primed lexical decision primarily reveals interlexical relationships rather than semantic processing. Joordens and Becker (1997) argued that the type of processing involved in the lexical decision task will vary, with semantic processing observed only 
under conditions that slow processing, such as discriminating between words and pseudowords (see also Williams, 1996). Finally, in three independent studies that employed quite different techniques, de Groot (1990), Becker et al. (1997), and Grainger and Frenck-Mestre (1998) showed that the primed lexical decision task is a less reliable indicator of semantic processing than is semantic categorization.

Jared and Seidenberg (1991) argued that the semantic categorization task itself may be contaminated by participant strategies, such as predicting the most frequent members of a given semantic category. Nonetheless, this problem can be easily avoided either by using a broad category, such as concrete/abstract (McRae \& Boisvert, 1998), or by including a wide range of exemplars for a specific category. The latter approach was adopted here. Another critique, levied by Wentura (2000) and Forster (2004), is that semantic categorization decisions are biased by response congruency. That is, on related trials, both prime and target are members of the same semantic category and call for the same categorical response, whereas on unrelated trials, the prime and target words are generally from different categories. If responses are driven in this strategic manner, then indeed, as both Lucas (2000) and Hutchison (2003) have claimed, results from this task will shed little light on the semantic organization of the lexicon. In the present study, we will examine both the efficiency of semantic categorization, as compared with primed lexical decision, and the response congruency hypothesis.

\section{The Present Study}

In eight experiments, we systematically compared two different prime-target relationships at increasing prime duration exposures, starting at $28 \mathrm{msec}$. This allowed us to pinpoint the onset of the facilitation of target processing, as well as possible differences in priming evolution as a function of prime-target relationship. To examine semantic priming, we used a translated subset of the McRae and Boisvert (1998) semantic-feature prime-target pairs, which were rated as having high semantic similarity but were not strongly associatively related. Associative priming was studied via a set of prime-target pairs that were rated relatively high on associative relatedness but comparatively low on semantic similarity. The selection of our materials was guided by several control experiments, described prior to Experiment 1. In Experiments 1-4, a semantic categorization task was used. In Experiments $5-7$, the primed lexical decision task replaced semantic categorization. The results of these seven experiments revealed that the onset of priming was earlier (1) for semantic-feature than for associative-semantic pairs and (2) in semantic categorization than in lexical decision. Finally, Experiment 8 enabled us to rule out the response congruency hypothesis as an account of facilitation for category coordinates in the semantic categorization task.

\section{GENERAL METHOD}

\section{Participants}

For all controls and experiments reported here, participants were recruited from a university population. Both sexes were represented, and the average age across experiments was 21 years, ranging from 19 to 23 . All participants were native French speakers, were naive with regard to the purpose of the experiment, and participated for course credit in only a single control study or experiment.

\section{Stimulus Selection}

Throughout the first seven experiments, two sets of 20 primetarget pairs were used: 20 associative-semantic pairs (see Appen$\operatorname{dix} \mathrm{A}$ ), for which the target was the first associate in the same semantic category as the prime (e.g., loup-renard "wolf-fox"), as well as 20 semantic-feature pairs (see Appendix B), for which the prime and target shared common features, according to production norms, and were category coordinates, but were not forward-associated according to published norms (e.g., baleine-dauphin "whale-dolphin"). The selection of these pairs, which involved three independent pilot experiments, is described below. Characteristics of the two types of pairs are presented in Table 1.

Twenty semantic-feature pairs were adopted from McRae and Boisvert (1998), who derived their materials from an earlier production study (McRae et al., 1997). In the latter study, prime-target pairs were created for concrete nouns that were category coordinates, shared at least two semantic features, and rated high on a 7-point similarity scale. From these materials, we selected pairs for which both the prime and the target could be unambiguously translated into the French language and that had several features in common (minimum of four features and mean of six, excluding superordinate information, across all pairs). The pairs were distributed across five semantic categories that included both natural categories and artifacts (i.e., clothing, animals, vegetables, vehicles, and weapons), with a minimum of 2 and a maximum of 6 critical prime-target pairs per semantic category. The length and frequency characteristics of the semantic-feature pairs are shown in Table 1 (with several sources of frequency information given). According to published norms in English and in French (Battig \& Montague, 1969; Tourette, 1979), 3 of the 20 target words were among the first 10 exemplars of their category, a further 8 ranked above the 20th exemplar, and the remaining 9 ranked above the 50th exemplar. In addition to the 20 test pairs, 80 filler pairs were created, spread across the same five semantic categories as the test pairs. For fillers, $27 \%$ were among the first 10 exemplars of their superordinate category, and the remaining $73 \%$ were among the first 50 exemplars. Frequency and word length of fillers were equated with target items.

Twenty associative-semantic pairs were selected according to both published French association norms (Ferrand \& Alario, 1998) and a pretest involving 31 native French participants. In the pretest, participants were asked to give the first association that came to mind for a list of 60 French words presented in a 60-page booklet (eight fixed random orders were used). Pairs were selected that ranked high in associative relatedness and were category coordinates. An example is the pair fenetre-porte ("window-door"); our pretest showed that the word porte was given as an associate to fenetre by $45 \%$ of participants, and it ranked second in the published norms (Ferrand \& Alario, 1998). Across all pairs, the selected associate was produced by $18 \%$ of the participants, which is roughly equivalent to the percentage found for second associates (Ferrand \& Alario, 1998; Moss \& Older, 1996; Spence \& Owens, 1990) and is comparable to that generally guaranteed in studies of priming. The length and frequency characteristics for the associative-semantic pairs are shown in Table 1 (once again with several sources of frequency given). These pairs were also distributed across five semantic categories (body parts, colors, animals, clothing, and parts of a building). There were a minimum of 2 and a maximum of 6 prime-target pairs per semantic category. Fourteen of the 20 target words were among the first 10 exemplars of their category, and the remaining 6 ranked above the 30th exemplar (Battig \& Montague, 1969; Tourette, 1979). These pairs were thus slightly more dominant members of their semantic category than were the semanticfeature pairs. In addition to the 20 associative-semantic pairs, 80 filler prime-target pairs, taken from the same five categories and matched in printed frequency, length, and category dominance to the targets, served as distractor trials throughout the series of experiments. 
Table 1

Characteristics of the Two Types of Pairs, With Comparisons With Other Studies

\begin{tabular}{|c|c|c|c|c|}
\hline & \multicolumn{2}{|c|}{ Semantic-Feature Pairs } & \multicolumn{2}{|c|}{ Associative-Semantic Pairs } \\
\hline & Prime & Target & Prime & Target \\
\hline Letters & $5.5(3-8)$ & $6.7(5-9)$ & $5.5(3-10)$ & $5.2(3-10)$ \\
\hline \multicolumn{5}{|l|}{ Frequency } \\
\hline $\begin{array}{l}\text { Source A } \\
\text { Source B } \\
\text { Source C }\end{array}$ & $\begin{array}{l}17.9(1-68.8) \\
16.1(1-44.3) \\
15.2(1-53.1)\end{array}$ & $\begin{array}{c}8.9(1-51.8) \\
8.9(1-40) \\
13.1(1-78.3)\end{array}$ & $\begin{array}{l}67.4(1-208.7) \\
47.8(2.1-199.4) \\
20.1(1.6-65.9)\end{array}$ & $\begin{array}{c}146.2(7.9-637.9) \\
148.7(4.4-861.7) \\
70.8(3-453.9)\end{array}$ \\
\hline \multicolumn{5}{|c|}{ Associative Relatedness } \\
\hline $\begin{array}{l}\text { Source D } \\
\text { Source E }\end{array}$ & \multicolumn{2}{|c|}{$\begin{array}{l}\text { n.a. } \\
0.75 \%(0 \%-4.5 \%)\end{array}$} & \multicolumn{2}{|c|}{$\begin{array}{l}24.4 \%(9.7 \%-61.8 \%) \\
\text { n.a. }\end{array}$} \\
\hline \multicolumn{5}{|c|}{ Semantic Similarity Ratings (Control Study 2) } \\
\hline $\begin{array}{l}\text { Source D } \\
\text { Source F }\end{array}$ & $\begin{array}{l}5.1 / 7(3.16-5.9 \\
6.2 / 9\end{array}$ & , $\mathrm{Mdn}=5.19$ & \multicolumn{2}{|c|}{$\begin{array}{l}4.26 / 7(2.25-5.87), \mathrm{Mdn}=4.07 \\
\text { n.a. }\end{array}$} \\
\hline \multicolumn{5}{|c|}{ Rank of Prime-Target } \\
\hline & Prime & Target & Prime & Target \\
\hline $\begin{array}{l}\text { Source G } \\
\text { Source H }\end{array}$ & $\begin{array}{l}20.6 \\
14.5\end{array}$ & $\begin{array}{l}24.9 \\
17.6\end{array}$ & $\begin{array}{l}14.1 \\
13.45\end{array}$ & $\begin{array}{l}10.6 \\
11.25\end{array}$ \\
\hline
\end{tabular}

Note-Ranges are in parentheses. Source A, BRULEX (Content, Mousty, \& Radeau, 1990), derived from Imbs, Martin, and the Centre de Recherche pour un Trésor de la Langue Française (1971); Source B, LEXIQUE 3.0, Book frequency (New, Pallier, Ferrand, \& Matos, 2001); Source C, LEXIQUE 3.0, Subtitle frequency (New et al., 2001); Source D, the present study; Source E, Ferrand and Alario (1998); Source F, McRae and Boisvert (1998); Source G, Battig and Montague (1969); Source H, Van Overschelde, Rawson, and Dunlosky (2004).

\section{Semantic Similarity Control Studies}

Two additional controls of the semantic characteristics of our materials were performed. The first provided a measure of the feature overlap of the associative-semantic pairs we created, and the second allowed us to directly compare the subjective ratings of semantic similarity for the semantic-feature and associative-semantic pairs. The results, reported below, revealed quantifiable differences between the associative-semantic and semantic-feature pairs that were used throughout the main study.

Control 1. This production study examined the feature overlap of the associative-semantic pairs. Sixty French university students were requested to list as many features as possible for the 20 prime and 20 target words of the associative-semantic pairs, as well as for the 60 filler items. Each word was printed individually on a page in a 100-page booklet (10 fixed random orders were used), and an example (e.g., "giraffe") showing both major category information ("is a mammal") and specific traits ("has a long neck," "has spots") was given on the first page. Participants were requested to list as many features as possible for each word. On average, participants provided at least seven features per item. Participants' responses revealed that the same superordinate category was produced independently for the prime and target words in 38 of the 40 cases (e.g., corps "body" was given for both doigt "finger" and pouce "thumb"). Aside from the common superordinate, however, the majority of the associative-semantic pairs (17 of the 20) did not elicit similar responses for the prime and the target, and among the remaining 3 pairs, none elicited more than two common traits for the prime and target. The associative-semantic pairs thus did not enjoy a high degree of feature overlap, according to our control study. Comparison of our results with other norms (McRae, Cree, Seidenberg, \& McNorgan, 2005) proved limited, because fewer than one third (6 pairs) of the materials we created were present in the other study.

Control 2. The second control study aimed to establish semantic similarity ratings for our materials in French. Both the 20 associative-semantic pairs and the 20 semantic-feature pairs adapted from McRae and Boisvert (1998) were tested. Forty-eight French participants were asked to rank these 40 pairs on a 7-point scale, from 1 (not at all semantically similar) to 7 (highly semantically similar). Specific examples were given, in order to avoid scoring based on asso- ciative relatedness. All 40 pairs were presented individually on a page in a booklet, in one of eight fixed random orders. No time limit was imposed, but participants were instructed to rate the different pairs according to their first impression with regard to semantic overlap. The results of this posttest matched the similarity ratings reported by McRae and Boisvert for their semantic-feature pairs in English, and also corroborated the results of our first control study regarding the feature overlap of our associative-semantic pairs. The range of scores for each group of pairs is presented in Figure 1. As can be seen, the two sets of stimuli were rated differently; participants almost exclusively used the higher end of the scale for the semantic-feature pairs, which were given scores of 5 or 6 for $80 \%$ of all pairs ( $50 \%$ were rated 6 ), whereas the associative-semantic pairs were rated lower overall, with $50 \%$ of all pairs rated from 2 to $4,35 \%$ rated 5 , and only $15 \%$ rated 6 . This difference was confirmed by a Kolmogorov-Smirnov test $(p<$ .05 ) comparing the distributions of the two populations.

\section{Tasks and Design}

Two tasks were employed: a primed semantic categorization and a primed lexical decision task.

In the semantic categorization task, participants were instructed to categorize words according to their superordinate category, which was presented only once, at the outset of each list. The experiment began with the visual presentation of a semantic category name on the CRT screen (e.g., ANIMAL) along with the instruction to press a key to begin a list. Following the initial category name, 20 prime-target trials were presented in random order, half requiring a positive and half a negative response. A trial consisted of a forward mask (13 hash marks) for $500 \mathrm{msec}$, followed by a prime word, in lowercase; then a backward mask (hash marks) from 14 to $57 \mathrm{msec}$, depending on the experiment; and the target word, in lowercase, which remained on the screen until the participant responded. The participants were instructed to indicate, via two response keys, whether the target word was a member of the prespecified semantic category. Critical trials always required a positive response, which was made with the dominant hand. The intertrial interval was $2 \mathrm{sec}$. Following the last target word of each category, the name of the following category appeared on the screen (e.g., VEGETABLE). The participant could then continue the experiment, by pressing the space bar, or take a break. 


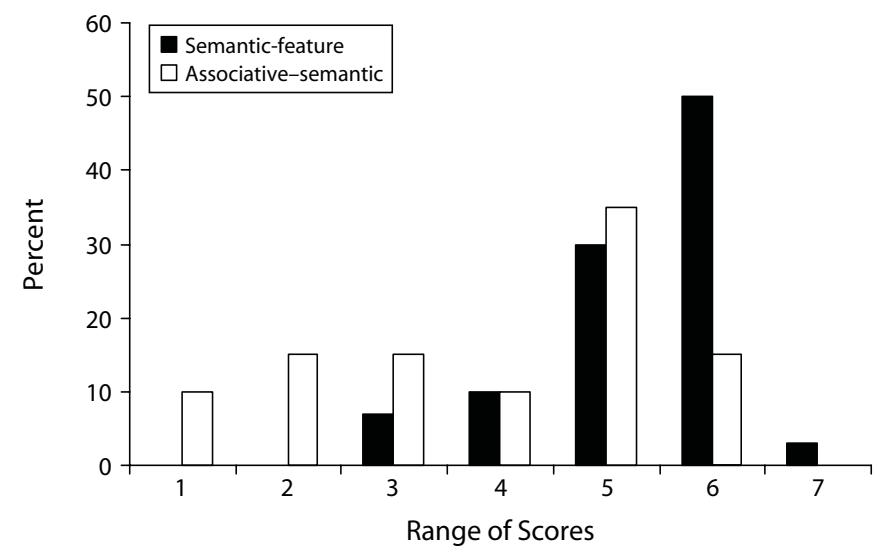

Figure 1. Similarity ratings for the stimuli on a 7-point scale, according to lexical relationship.

In the primed lexical decision task, the sequence of stimuli was the same as in the semantic categorization task. A forward mask (13 hash marks) was presented for $500 \mathrm{msec}$, followed by a prime word, in lowercase; then a backward mask (hash marks) from 14 to $57 \mathrm{msec}$, depending on the experiment; and the target word, in lowercase, which remained on the screen until the participant's response. The use of the backward mask avoided the physical continuation of the prime on trials in which the prime and target words were identical, rather than changing case (see Forster, Mohan, \& Hector, 2003). All prime-target pairs were presented as individual trials within a list, with a different random order of presentation per participant. No regrouping of pairs according to semantic categories was performed. The intertrial interval was $2 \mathrm{sec}$.

In both the semantic categorization and lexical decision tasks, the prime word was presented for $28,43,71$, or $199 \mathrm{msec}$ (with a backward mask of $14 \mathrm{msec}$ for the 28- and 43-msec presentations, $28 \mathrm{msec}$ for the 71-msec presentation, and $57 \mathrm{msec}$ for the $199-\mathrm{msec}$ presentation), according to the experiment. At the shortest prime exposures, participants were not informed of the presence of the prime word. At the longer prime exposures, participants were asked simply to read the prime to themselves.

\section{EXPERIMENT 1}

The first experiment examined priming given a semantic, nonassociative relationship, such as "whale-dolphin," in a semantic categorization task under conditions of masked priming ( 28 or $43 \mathrm{msec}$ ). As a control, we included identical pairs (e.g., "whale-whale"). Facilitation for these pairs would provide evidence that the prime word had been processed, despite the short prime exposures (Forster \& Davis, 1984). The experiment served as a direct extension of McRae and Boisvert (1998), who found priming for semantic, nonassociative pairs, but at a much longer prime exposure $(250 \mathrm{msec})$. Facilitation was also predicted to occur earlier for prime-target pairs with high semantic similarity (McRae \& Boisvert, 1998; Plaut, 1995), an issue that will be addressed in Experiments 3 and 4.

\section{Method}

Participants. Sixteen French university students participated in the experiment, which lasted roughly $50 \mathrm{~min}$.

Materials and Design. The 20 semantic-feature pairs and 80 filler pairs were presented in five blocked semantic categories of equal size.
The test pairs were always seen within their semantic category. Four lists were created, such that all 20 target words were seen in all four prime conditions, defined by prime relatedness (related vs. unrelated) and prime type (identical vs. semantic), but only in one condition per list. Each list was presented twice at each prime duration (28 and $43 \mathrm{msec}$ ). Hence, prime words were seen twice by each participant, once at each prime duration, whereas the target words were seen eight times by each participant. Both the order of presentation of the lists and the order of prime durations were counterbalanced across participants.

Procedure. The task was semantic categorization.

\section{Results}

Repeated measures ANOVAs were performed on mean RTs for correct responses between 300 and $1,000 \mathrm{msec}$ (6.5\% of the data were excluded, $4.5 \%$ because of error) and on error rates. Prime type (identical vs. semanticfeature), prime relatedness (related vs. unrelated), and prime duration ( 28 vs. $43 \mathrm{msec}$ ) were repeated measures, with participants and items as sources of variance. The mean RTs and error rates are presented in Table 2 as a function of the experimental factors.

Main effects emerged for prime type $\left[F_{1}(1,15)=4.71\right.$, $M S_{\mathrm{e}}=3,179.82, p<.04 ; F_{2}(1,19)=6.34, M S_{\mathrm{e}}=645.32$, $p<.02]$ and prime relatedness $\left[F_{1}(1,15)=65.45, M S_{\mathrm{e}}=\right.$ $1,775.47, p<.001 ; F_{2}(1,19)=58.80, M S_{\mathrm{e}}=695.76, p<$ $.001]$. The effect of prime duration was not significant $\left[F_{1}<1 ; F_{2}(1,19)=2.61, M S_{\mathrm{e}}=673.39, p<.1\right]$. The effect of prime relatedness was not significantly modified in the by-participants analysis by either prime type $\left[F_{1}(1,15)=1.07, M S_{\mathrm{e}}=2,060.58\right.$, n.s.; $F_{2}(1,19)=7.53$, $\left.M S_{\mathrm{e}}=635.79, p<.01\right]$ or prime duration $\left[F_{1}(1,15)=\right.$ $1.31, M S_{\mathrm{e}}=1,845.74$, n.s.; $F_{2}(1,19)=5.89, M S_{\mathrm{e}}=$ $401.71, p<.025]$. No other effects were significant $\left(F_{1}\right.$ and $F_{2}<1$ for all other effects), nor did the analysis of errors reveal any effects.

Given the theoretical importance of these results, independent analyses were performed on the data obtained for each of the two prime types. For semantic-feature pairs, a main effect of prime relatedness was observed $\left[F_{1}(1,15)=22.37, M S_{\mathrm{e}}=1,771.61, p<.001 ; F_{2}(1,19)=\right.$ 21.36, $\left.M S_{\mathrm{e}}=414.23, p<.001\right]$, which did not interact 
Table 2

Experiments 1-7: Mean Response Times (in Milliseconds), Standard Deviations and Error Rates to Target Words, As Functions of Task, Prime Type, Prime Relatedness, and Prime Duration

\begin{tabular}{|c|c|c|c|c|c|c|c|c|}
\hline Prime Dur. & Prime Rel. & RT & $S D$ & $\% \mathrm{E}$ & Prime Rel. & RT & $S D$ & $\% \mathrm{E}$ \\
\hline \multicolumn{9}{|c|}{ Experiments 1-4: Semantic Categorization } \\
\hline \multirow{4}{*}{$\begin{array}{l}\text { Experiment } 1 \\
28 \mathrm{msec}\end{array}$} & \multicolumn{4}{|c|}{ Semantic-Feature } & \multicolumn{4}{|c|}{ Repetition } \\
\hline & Related & 572 & 71 & 4.7 & Identical & 559 & 83 & 3.4 \\
\hline & Unrelated & 594 & 73 & 4.7 & Unrelated & 588 & 90 & 5.0 \\
\hline & Effect & 22 & & & Effect & 29 & & \\
\hline \multirow[t]{3}{*}{$43 \mathrm{msec}$} & Related & 569 & 79 & 4.7 & Identical & 550 & 102 & 3.7 \\
\hline & Unrelated & 596 & 92 & 4.7 & Unrelated & 592 & 83 & 4.6 \\
\hline & Effect & 33 & & & Effect & 42 & & \\
\hline \multirow{4}{*}{$\begin{array}{l}\text { Experiment } 2 \\
28 \mathrm{msec}\end{array}$} & \multicolumn{4}{|c|}{ Associative-Semantic } & \multicolumn{4}{|c|}{ Repetition } \\
\hline & Related & 569 & 90 & 1.5 & Identical & 547 & 85 & 2.2 \\
\hline & Unrelated & 560 & 90 & 1.8 & Unrelated & 561 & 88 & 1.8 \\
\hline & Effect & -9 & & & Effect & 14 & & \\
\hline \multirow[t]{3}{*}{$43 \mathrm{msec}$} & Related & 559 & 71 & 1.5 & Identical & 527 & 69 & 0.8 \\
\hline & Unrelated & 560 & 61 & 0.9 & Unrelated & 551 & 56 & 3.4 \\
\hline & Effect & 1 & & & Effect & 24 & & \\
\hline \multirow{4}{*}{$\begin{array}{c}\text { Experiment } 3 \\
71 \mathrm{msec}\end{array}$} & \multicolumn{4}{|c|}{ Associative-Semantic } & \multicolumn{4}{|c|}{ Semantic-Feature } \\
\hline & Related & 581 & 74 & 2.0 & Related & 622 & 75 & 8.5 \\
\hline & Unrelated & 601 & 55 & 3.0 & Unrelated & 646 & 63 & 7.0 \\
\hline & Effect & 20 & & & Effect & 24 & & \\
\hline \multirow{5}{*}{$\begin{array}{c}\text { Experiment } 4 \\
199 \mathrm{msec}\end{array}$} & \multicolumn{4}{|c|}{ Associative-Semantic } & \multicolumn{4}{|c|}{ Semantic-Feature } \\
\hline & Related & 583 & 74 & 1.8 & Related & 607 & 83 & 4.5 \\
\hline & Unrelated & 601 & 79 & 4.5 & Unrelated & 658 & 81 & 7.0 \\
\hline & Effect & 18 & & & Effect & 51 & & \\
\hline & \multicolumn{7}{|c|}{ Experiments 5-7: Primed Lexical Decision } & \\
\hline \multirow{4}{*}{$\begin{array}{l}\text { Experiment } 5 \\
28 \mathrm{msec}\end{array}$} & \multicolumn{4}{|c|}{ Associative-Semantic } & \multicolumn{4}{|c|}{ Semantic-Feature } \\
\hline & Related & 543 & 45 & 1.4 & Related & 607 & 64 & 8.5 \\
\hline & Unrelated & 541 & 49 & 0.6 & Unrelated & 601 & 61 & 10.0 \\
\hline & Effect & -2 & & & Effect & -6 & & \\
\hline \multirow[t]{3}{*}{$43 \mathrm{msec}$} & Related & 548 & 59 & 1.25 & Related & 608 & 57 & 9.2 \\
\hline & Unrelated & 550 & 49 & 1.6 & Unrelated & 604 & 60 & 8.0 \\
\hline & Effect & 2 & & & Effect & -4 & & \\
\hline \multirow{4}{*}{$\begin{array}{l}\text { Experiment } 6 \\
71 \mathrm{msec}\end{array}$} & \multicolumn{4}{|c|}{ Associative-Semantic } & \multicolumn{4}{|c|}{ Semantic-Feature } \\
\hline & Related & 581 & 64 & 1.5 & Related & 646 & 58 & 8.5 \\
\hline & Unrelated & 604 & 62 & 3.0 & Unrelated & 660 & 57 & 8.5 \\
\hline & Effect & 23 & & & Effect & 16 & & \\
\hline \multirow{4}{*}{$\begin{array}{c}\text { Experiment } 7 \\
199 \mathrm{msec}\end{array}$} & \multicolumn{4}{|c|}{ Associative-Semantic } & & antic-l & ture & \\
\hline & Related & 568 & 93 & 1.75 & Related & 662 & 94 & 4.75 \\
\hline & Unrelated & 616 & 73 & 4.0 & Unrelated & 688 & 98 & 7.0 \\
\hline & Effect & 48 & & & Effect & 26 & & \\
\hline
\end{tabular}

with prime duration $\left(F_{1}\right.$ and $\left.F_{2}<1\right)$. Tests of simple effects revealed main effects of prime relatedness at both $28 \mathrm{msec}\left[F_{1}(1,15)=14.78, M S_{\mathrm{e}}=1,108.20, p<.001\right.$; $\left.F_{2}(1,19)=6.49, M S_{\mathrm{e}}=451.94, p<.02\right]$ and $43 \mathrm{msec}$ $\left[F_{1}(1,15)=12.66, M S_{\mathrm{e}}=1,862.86, p<.002 ; F_{2}(1,19)=\right.$ $\left.8.73, M S_{\mathrm{e}}=712.62, p<.01\right]$. For identical pairs, a main effect of prime relatedness was observed $\left[F_{1}(1,15)=\right.$ $38.79, M S_{\mathrm{e}}=2,064.43, p<.001 ; F_{2}(1,19)=40.16$, $\left.M S_{\mathrm{e}}=917.32, p<.001\right]$, which interacted with prime duration only in the by-items analysis $\left[F_{1}(1,15)=1.18\right.$, $M S_{\mathrm{e}}=2,226.86, p<.2 ; F_{2}(1,19)=5.21, M S_{\mathrm{e}}=505.49$, $p<.03]$. Tests of simple effects revealed main effects of repetition at $28 \mathrm{msec}\left[F_{1}(1,15)=11.32, M S_{\mathrm{e}}=2,368.138\right.$, $\left.p<.004 ; F_{2}(1,19)=13.90, M S_{\mathrm{e}}=710.43, p<.001\right]$ and $43 \mathrm{msec}\left[F_{1}(1,15)=29.07, M S_{\mathrm{e}}=1,923.15, p<.001\right.$; $\left.F_{2}(1,19)=41.54, M S_{\mathrm{e}}=712.38, p<.001\right]$.

\section{Discussion}

The results show, first, a robust effect of repetition priming under masked priming conditions, here in a semantic categorization task. More importantly, facilitation was also obtained for prime-target pairs that shared semantic features. Priming was evidenced for these pairs as early as $28 \mathrm{msec}$ of masked prime presentation. This result extends previous findings for this type of relationship (Cree et al., 1999; McRae \& Boisvert, 1998) and demonstrates that the semantic network can be activated, even at very brief presentations, given sufficient semantic similarity. ${ }^{2}$ It is highly probable that the characteristics of the task also played an important role, in that the retrieval and use of semantic information was mandatory (Becker et al., 1997; Grainger \& Frenck-Mestre, 1998). The issue of task demands will be taken up in Experiments 5-8. 
Further discussion of the results will be elaborated in the General Discussion.

\section{EXPERIMENT 2}

Priming facilitation was now examined under the same masked conditions and task (semantic categorization) as in Experiment 1, but for prime-target pairs that were associatively related. The pairs were semantically related by virtue of being category coordinates, but they had low semantic similarity. They were thus characterized by being weakly semantically similar while being relatively strongly associatively related, as determined by our pilot experiments and published norms (Ferrand \& Alario, 1998).

These pairs provided a clear means of testing, first, the hypothesis that priming facilitation between word pairs is enhanced by associative relatedness (see Hutchison, 2003, and Lucas, 2000, for opposing views). Rather than trying to eliminate the effect of this factor, the present materials allowed us to determine whether associative relatedness would produce facilitation under masked priming conditions in the absence of strong semantic similarity. An absence of priming for the present pairs would support the hypothesis that the facilitation observed in Experiment 1 was indeed the product of semantic similarity rather than of the materials' weak associative relatedness. The second hypothesis we tested concerned the role of the superordinate category: If priming in Experiment 1 was the product of the category membership rather than the semantic similarity of the pairs, the present materials should produce facilitation. An absence of facilitation, again, would reinforce the claim that the results obtained in Experiment 1 were due to semantic similarity between the prime and target rather than to their category membership in and of itself. This question will be addressed further in Experiment 8. As in Experiment 1, a control of prime processing was performed by testing for repetition priming.

\section{Method}

Participants. Sixteen French university students participated in the experiment, which lasted roughly $50 \mathrm{~min}$.

Materials and Design. The critical trials consisted of the 20 associative-semantic pairs and were mixed with 80 filler trials distributed equally across five semantic categories. The test pairs were always seen within their semantic category. The design was identical to that of Experiment 1.

Procedure. The task was semantic categorization.

\section{Results}

Repeated measures ANOVAs were carried out on RTs for correct answers between 300 and 1,000 msec (this excluded $3 \%$ of the data, $2 \%$ from errors) and on error rates. Prime type (identical vs. associative-semantic), prime relatedness (related vs. unrelated), and prime duration ( 28 vs. $43 \mathrm{msec}$ ) were repeated measures, with items and participants as sources of variance. The mean RTs and error rates are presented in Table 2 as a function of the experimental factors.

Prime duration was not significant $\left(F_{1}\right.$ and $\left.F_{2}<1\right)$, nor did it interact with any other factor. Prime type reached significance by participants $\left[F_{1}(1,15)=30.50, M S_{\mathrm{e}}=\right.$ 974.24, $p<.001 ; F_{2}(1,19)=3.24, M S_{\mathrm{e}}=2,686.18, p<$ $.09]$, prime relatedness did so by items $\left[F_{1}(1,15)=2.99\right.$, $M S_{\mathrm{e}}=2,258.65, p<.10 ; F_{2}(1,19)=5.44, M S_{\mathrm{e}}=445.91$, $p<.03$ ], and there was a significant interaction between the two factors $\left[F_{1}(1,15)=9.28, M S_{\mathrm{e}}=1,791.94, p<\right.$ $\left..01 ; F_{2}(1,19)=5.48, M S_{\mathrm{e}}=976.30, p<.03\right]$. Independent analyses for the two prime types revealed a significant effect of repetition priming $\left[F_{1}(1,15)=17.47, M S_{\mathrm{e}}=\right.$ $1,276.33, p<.001 ; F_{2}(1,19)=11.10, M S_{\mathrm{e}}=675.34, p<$ $.003]$, which did not interact with prime duration $\left[F_{1}<1\right.$; $F_{2}(1,19)=1.30, M S_{\mathrm{e}}=683.54$, n.s. $]$. No effect of priming was observed for the associative-semantic pairs ${ }^{3}\left(F_{1}\right.$ and $\left.F_{2}<1\right)$, nor did prime relatedness interact with prime duration $\left[F_{1}(1,15)=1.58, M S_{\mathrm{e}}=1,131.04\right.$, n.s.; $\left.F_{2}<1\right]$. The analysis of errors revealed no significant effects.

\section{Discussion}

The results are clear. Repetition priming was found, indicating that the prime word was processed sufficiently to facilitate the subsequent processing of the target word. However, when the prime word was not identical to the target word but was an associate of the target from the same semantic category (e.g., loup-renard "wolf-fox"), no reliable effect of priming was observed. This contrasts with the results obtained in Experiment 1 for the semanticfeature pairs, which produced facilitation under the same conditions. Note, however, that our associative-semantic pairs ranked overall as second associates; it is conceivable that had we used primary associates, rather than the first associates within the same semantic category, we would not have observed exactly the same pattern of results.

Our results contrast with those reported by Moss et al. (1995), who showed priming for category coordinates only when the two words were associatively related. Our data, on the other hand, show no facilitation for our associatively related category coordinate pairs. Although comparison between the two studies is limited by a difference in the procedures (Moss et al. [1995] used a continuous lexical decision task), the diverging results are nonetheless puzzling (but see McRae \& Boisvert [1998] for a discussion of Moss et al.'s [1995] materials). Prior to making any strong claims on the basis of the present results, however, it is necessary to establish that the associative-semantic pairs we used could indeed produce facilitation under less extreme conditions. Experiments 3 and 4 were performed with this aim.

\section{EXPERIMENT 3}

The third experiment aimed, first, to determine whether an effect of priming would be produced by the associativesemantic pairs used in Experiment 2, provided that more time was available for prime processing. A 99-msec SOA was therefore used, a period generally considered to guarantee automatic processing (Neely, 1991; Neely \& Kahan, 2001). The second objective was to directly compare, in a within-participants design, the effect of priming produced by our associative-semantic pairs with that produced by the semantic-feature pairs. 


\section{Method}

Participants. Twenty French university students participated in the experiment, which lasted roughly $10 \mathrm{~min}$.

Materials and Design. The 20 semantic-feature pairs and the 20 associative-semantic pairs were presented, in addition to 160 filler pairs. Two lists were prepared, such that each target was seen in each of two prime conditions (related vs. unrelated), but in only one condition per list. Each list consisted of 200 prime-target trials, divided into ten 20 -trial blocks defined by semantic categories. A given participant saw only one experimental list. A single, 99-msec SOA was used (71-msec prime, 28-msec backward mask).

Procedure. The task was semantic categorization.

\section{Results}

Repeated measures ANOVAs were conducted on the RTs for correct answers between 300 and 1,000 msec (this excluded $8.75 \%$ of the data overall, $5.25 \%$ from errors) and on error rates. Prime type (semantic-feature vs. associative-semantic) and prime relatedness (related vs. unrelated) were repeated measures, with participants and items as sources of variance and list as a dummy variable. The results are presented in Table 2 as a function of the experimental factors.

Main effects emerged for prime relatedness $\left[F_{1}(1,18)=\right.$ $12.26, M S_{\mathrm{e}}=787.78, p<.002 ; F_{2}(1,38)=7.60, M S_{\mathrm{e}}=$ $1,084.03, p<.01]$ and prime type $\left[F_{1}(1,18)=15.95\right.$, $M S_{\mathrm{e}}=2,311.50, p<.001 ; F_{2}(1,38)=9.20, M S_{\mathrm{e}}=$ $4,384.63, p<.004]$, with no reliable interaction $\left(F_{1}\right.$ and $\left.F_{2}<1\right)$. Nonetheless, to establish the effect of priming for the associative-semantic pairs, planned comparisons were carried out on the data for each prime type. For the associative-semantic pairs, the effect of priming was reliable $\left[F_{1}(1,18)=5.95, M S_{\mathrm{e}}=646.79, p<.025 ; F_{2}(1,19)=\right.$ 4.67, $\left.M S_{\mathrm{e}}=780.82, p<.04\right]$. For the semantic-feature pairs, priming was reliable by participants and produced a trend by items $\left[F_{1}(1,18)=12.67, M S_{\mathrm{e}}=467.15, p<\right.$ $\left..001 ; F_{2}(1,19)=3.32, M S_{\mathrm{e}}=1,387.23, p<.08\right]$.

The analysis of errors revealed only an effect of prime type $\left[F_{1}(1,18)=14.71, M S_{\mathrm{e}}=.004, p<.001 ; F_{2}(1,38)=\right.$ $\left.5.23, M S_{\mathrm{e}}=.011, p<.03\right]$. More errors were made in categorizing semantic-feature targets $(7.75 \%)$ than associative-semantic targets $(2.5 \%)$, undoubtedly because of the lower average frequency of the former target words (which were adapted from English materials).

\section{Discussion}

Our results demonstrate that priming can be obtained for the associative-semantic pairs we selected. However, priming for these pairs occurred only under conditions in which the prime word was presented for a relatively long duration. ${ }^{4}$ In contrast, the reliable priming effect we found for the semantic-feature pairs extended that found in Experiment 1, which occurred as early as $28 \mathrm{msec}$ of prime presentation. Considered together, the results from these three experiments strongly suggest that associative relatedness in the absence of a high degree of semantic similarity is not sufficient to rapidly influence target word processing in a task that necessitates the retrieval of semantic information. The implications of these results will be discussed further in the General Discussion.

\section{EXPERIMENT 4}

A final experiment, with the same task and materials but a longer prime-target SOA, was performed in order to examine whether the semantic-feature and associativesemantic pairs would reveal different patterns of priming under conditions in which the prime could be fully processed. Plaut's (1995) simulations suggest just that. That is, whereas semantic overlap should produce greater priming than associative relatedness at short SOAs, the inverse should be observed at longer SOAs, because of the mechanisms purportedly involved in priming. A single, 256-msec SOA was used to test these predictions.

\section{Method}

Participants. Forty French university students participated in the experiment, which lasted roughly $10 \mathrm{~min}$.

Materials and Design. These were identical to those of Experiment 3, with the exception of the SOA, which was $256 \mathrm{msec}$ (199-msec prime, 57-msec backward mask).

Procedure. The task was semantic categorization.

\section{Results}

Repeated measures ANOVAs were conducted on the RTs for correct responses between 300 and 1,000 msec (this excluded $9.5 \%$ of the data overall, with $4.4 \%$ from errors) and on the error data. Prime type (semantic-feature vs. associative-semantic) and prime relatedness (related vs. unrelated) were repeated measures, with participants and items as sources of variance and list as a dummy variable. The mean RTs and error rates are presented in Table 2 as a function of the experimental factors.

Main effects emerged for prime relatedness $\left[F_{1}(1,38)=\right.$ $23.43, M S_{\mathrm{e}}=2,047.37, p<.001 ; F_{2}(1,38)=18.21, M S_{\mathrm{e}}=$ $1,281.59, p<.001]$ and prime type $\left[F_{1}(1,38)=33.19, M S_{\mathrm{e}}=\right.$ $1,981.12, p<.001 ; F_{2}(1,38)=8.38, M S_{\mathrm{e}}=4,088.07, p<$ $.01]$, with a reliable interaction between the two $\left[F_{1}(1,38)=\right.$ $7.91, M S_{\mathrm{e}}=1,325.36, p<.01 ; F_{2}(1,38)=4.07, M S_{\mathrm{e}}=$ $1,281.59, p<.05]$. Priming facilitation was greater and more reliable for the semantic-feature pairs $\left[F_{1}(1,38)=\right.$ $20.77, M S_{\mathrm{e}}=2,486.38, p<.001 ; F_{2}(1,19)=16.02, M S_{\mathrm{e}}=$ $1,580.07, p<.001]$ than for the associative-semantic pairs $\left[F_{1}(1,38)=7.67, M S_{\mathrm{e}}=886.36, p<.01 ; F_{2}(1,19)=3.30\right.$, $\left.M S_{\mathrm{e}}=983.12, p<.08\right]$.

The analysis of errors revealed effects of prime relatedness $\left[F_{1}(1,38)=8.32, M S_{\mathrm{e}}=.0033, p<.01 ; F_{2}(1,38)=9.53\right.$, $\left.M S_{\mathrm{e}}=.0014, p<.01\right]$ and prime type $\left[F_{1}(1,38)=7.49\right.$, $M S_{\mathrm{e}}=.0037, p<.01 ; F_{2}(1,38)=2.25, M S_{\mathrm{e}}=.0061, \mathrm{n} . \mathrm{s}$.] by participants. Fewer errors were made on related as compared with unrelated prime-target trials and on semantic-feature as compared with associative-semantic targets.

\section{Discussion}

The results, obtained in a task that mandated the processing of semantic information, showed greater priming for semantic-feature than for associative-semantic pairs at a relatively long SOA. A comparison of results obtained across the first four experiments clearly shows an earlier onset of priming for prime-target pairs created on 
the basis of semantic similarity and featural overlap than for merely associated pairs. However, contrary to the proposals from Plaut's (1995) simulations, our results do not show an earlier asymptote of priming for semantic-feature relationships than for associative-semantic relationships. ${ }^{5}$ Further discussion of these results will be postponed until the General Discussion.

\section{EXPERIMENT 5}

In the first four experiments, we used a semantic categorization task under the assumption that this task is relevant to the study of semantic memory, more so than the lexical decision task (Becker et al., 1997; Grainger \& Frenck-Mestre, 1998). On the basis of McRae and Boisvert's (1998) results, however, it might be argued that this assumption is invalid. Those authors found that primes facilitated target processing when the two shared strong semantic similarity, both in a semantic categorization task and in a primed lexical decision task. However, their results were obtained under conditions in which the prime word was clearly visible (250-msec SOA), whereas Grainger and Frenck-Mestre demonstrated that when the prime is masked, priming facilitation is obtained earlier and more reliably in a semantic categorization rather than a lexical decision task. The present experiment aimed to establish whether our materials would produce priming, under masked conditions, in a lexical decision task.

\section{Method \\ Participants. Twenty-four French students participated in the experiment, which lasted roughly $55 \mathrm{~min}$. \\ Materials and Design. The critical trials included the 20 semantic- feature and 20 associative-semantic pairs. The two types of pairs were seen in independent lists. For each type of pair, two counterbalanced lists were created, such that all target words were seen in both prime condi- tions (related and unrelated), but in only one condition per list. Each list was presented twice, once at each prime duration ( 28 and $43 \mathrm{msec}$ ). All participants saw all four lists, for both the semantic-feature and associative-semantic pairs. The orders of presentation of the lists and of the prime durations were counterbalanced across participants. In any given list were 20 critical pairs (10 related, 10 unrelated), 40 unrelated filler pairs, and 60 prime-pseudoword pairs; thus, less than $10 \%$ of a list consisted of related trials. Nonwords were orthographically and pho- nologically legal strings in French and were created by changing one or two letters of a French lexical item that was matched to the target words in frequency and length.}

Procedure. The task was primed lexical decision.

\section{Results}

ANOVAs were performed on the mean RTs for correct answers between 300 and $1,000 \mathrm{msec}$ (which excluded $9 \%$ of the data, $7 \%$ from errors) and on error rates. Participants and items were used as sources of variance and prime type (semantic-feature vs. associative-semantic), prime relatedness (related vs. unrelated), and prime duration $(28 \mathrm{vs} .43 \mathrm{msec})$ as repeated measures. The means are presented as a function of the experimental factors in Table 2.

An effect of prime type emerged $\left[F_{1}(1,23)=92.88\right.$, $M S_{\mathrm{e}}=3,626.95, p<.001 ; F_{2}(1,38)=34.15, M S_{\mathrm{e}}=$ $4,652.91, p<.001]$. Target words were identified faster for the associative-semantic than for the semantic-feature pairs (546 vs. $605 \mathrm{msec}$ ). No other effects were reliable. The analysis of errors also revealed the effect of prime type $\left[F_{1}(1,23)=55.01, M S_{\mathrm{e}}=.0101, p<.001 ; F_{2}(1,38)=\right.$ $\left.4.99, M S_{\mathrm{e}}=.0463, p<.03\right]$. Fewer errors were made to targets from the associative-semantic pairs $(2 \%)$ than to those from the semantic-feature pairs $(9 \%)$.

For the semantic-feature pairs, we also conducted a between-task comparison. Item means obtained for these pairs in the present experiment and in Experiment 1 were subjected to a repeated measures ANOVA, involving prime relatedness (related vs. unrelated), prime duration (28 vs. $43 \mathrm{msec}$ ), and task (lexical decision vs. semantic categorization). The analysis revealed a significant task $\times$ prime relatedness interaction $\left[F_{2}(1,19)=18.09, M S_{\mathrm{e}}=148.68\right.$, $p<.001$ ], due to significant priming facilitation under semantic categorization $(p<.001)$ but not under lexical decision (2-msec effect, n.s.). It is thus clear that the same materials produced quite different effects across the tasks.

\section{Discussion}

Our results support the hypothesis that a lexical decision task is not the one best suited to reveal semantic processing. No facilitation was obtained in this task, for either the semantic-feature or associative-semantic pairs we created, when the prime was masked and presented very briefly. This result stands in stark contrast to the facilitation we obtained for the semantic-feature pairs under the same prime conditions in semantic categorization (Experiment 1). The pattern of results across experiments suggests, moreover, that the facilitation we obtained in our first experiment is the product of both task demands and the prime-target relationship. At very brief prime-target SOAs, both of these aspects must have strong semantic constraints for facilitation to be observed (see Grainger \& Frenck-Mestre, 1998, for similar results). At longer prime exposures, however, it is quite possible that the present materials would produce facilitation in a primed lexical decision task (see Grainger \& Frenck-Mestre, 1998; McRae \& Boisvert, 1998; Perea $\&$ Gotor, 1997; Perea \& Rosa, 2002). Experiments 6 and 7 examined this question.

\section{EXPERIMENT 6}

\section{Method}

Participants. Forty French students participated in the experiment, which lasted roughly $5 \mathrm{~min}$.

Materials and Design. The materials and design were identical to those of Experiment 5, with the exceptions that a single, 99-msec SOA (71-msec prime, 28-msec backward mask) was used and that each participant saw only one experimental list.

Procedure. The task was primed lexical decision.

\section{Results}

ANOVAs were performed on the mean RTs for correct answers between 300 and $1,000 \mathrm{msec}$ (this excluded 10.5\% of the data overall, all due to errors) and on error rates. Participants and items were used as sources of variance, prime type (semantic-feature vs. associative-semantic) as a between-participants factor, prime relatedness (related vs. unrelated) as a repeated measure, and list as a dummy 
variable. The means are presented as a function of the experimental factors in Table 2 .

Main effects emerged for prime type $\left[F_{1}(1,36)=10.41\right.$, $M S_{\mathrm{e}}=7,043.19, p<.002 ; F_{2}(1,38)=17.83, M S_{\mathrm{e}}=$ $664.24, p<.001]$ and prime relatedness $\left[F_{1}(1,36)=\right.$ $11.15, M S_{\mathrm{e}}=599.30, p<.002 ; F_{2}(1,38)=6.22, M S_{\mathrm{e}}=$ $1,476.94, p<.02]$, with no interaction $\left(F_{1}\right.$ and $\left.F_{2}<1\right)$. Lexical decision times were faster to targets from associative-semantic rather than from semantic-feature pairs (593 vs. $653 \mathrm{msec}$, respectively) and were accelerated by the prior presentation of a related as compared with an unrelated prime (614 vs. $632 \mathrm{msec}$, respectively).

The analysis of errors revealed only an effect of prime type $\left[F_{1}(1,36)=10.36, M S_{\mathrm{t}}=.007, p<.003 ; F_{2}(1,38)=\right.$ $\left.3.87, M S_{\mathrm{e}}=.020, p<.05\right]$. Fewer errors were made to targets from the associative-semantic pairs than from the semantic-feature pairs.

\section{Discussion}

Facilitation was obtained for both the semantic-feature and associative-semantic pairs in primed lexical decision with a 99-msec SOA. These results add to numerous others that have shown priming in lexical decision at SOAs from 50 to $100 \mathrm{msec}$ for various relationships, both within and across languages (see Neely, 1991, for earlier studies; see also de Groot, 1992; Frenck-Mestre \& Prince, 1997; Hodgson, 1991; Perea \& Gotor, 1997; Perea \& Rosa, 2002; Williams, 1994, 1996). The implications of these results will be discussed further in the General Discussion.

To provide a coherent picture of the results, a further experiment was conducted in which the same task (primed lexical decision) and materials were employed as in Experiments 5 and 6, but the prime-target SOA was increased to $256 \mathrm{msec}$, which matched that used in the semantic categorization task in Experiment 4.

\section{EXPERIMENT 7}

\section{Method}

Participants. Sixteen French students participated in the experiment, which lasted roughly $10 \mathrm{~min}$.

Materials and Design. These were the same as in Experiment 5, with the following exceptions: The 20 semantic-feature and 20 associative-semantic trials were included in the same list; the lists comprised 200 trials ( 40 critical trials [ 20 related, 20 unrelated], 60 unrelated filler trials, and 100 prime-pseudoword trials); and the prime-target SOA was $256 \mathrm{msec}$ (199-msec prime, 57-msec backward mask). As in Experiment 6, counterbalancing was performed such that all targets were seen in both prime conditions (related and unrelated) but in only one condition per list, and each participant received only one list.

Procedure. The task was primed lexical decision.

\section{Results}

Repeated measures ANOVAs were performed on the mean RTs for correct answers between 300 and $1,000 \mathrm{msec}$ (this excluded $9.5 \%$ of the data overall, $4 \%$ from errors) and on error rates. Participants and items were used as sources of variance, prime type (semantic-feature vs. associative-semantic) and prime relatedness (related vs. unrelated) as repeated measures, and list as a dummy variable. The means are presented in Table 2 as a function of the experimental factors.
Prime type produced a significant effect $\left[F_{1}(1,14)=\right.$ $57.70, M S_{\mathrm{e}}=1,927.41, p<.001 ; F_{2}(1,38)=26.84$, $\left.M S_{\mathrm{e}}=7,109.59, p<.001\right]$, as did prime relatedness $\left[F_{1}(1,14)=12.73, M S_{\mathrm{e}}=1,690.63, p<.003 ; F_{2}(1,38)=\right.$ $\left.8.75, M S_{\mathrm{e}}=1,947.30, p<.01\right]$. Lexical decision times were faster to targets from the associative-semantic rather than from the semantic-feature pairs $(592$ and $662 \mathrm{msec}$, respectively) and were accelerated by the prior presentation of a related as compared with an unrelated prime word (615 and $652 \mathrm{msec}$, respectively). The interaction between prime type and prime relatedness was significant only in the by-items analysis $\left[F_{1}(1,14)=1.21, M S_{\mathrm{e}}=1,655.28\right.$, n.s.; $\left.F_{2}(1,38)=4.54, M S_{\mathrm{七}}=1,947.30, p<.05\right]$. The effect of priming tended to be greater for the associativesemantic pairs $(48 \mathrm{msec})$ than for the semantic-feature pairs (26 msec).

The analysis of errors revealed only an effect of prime type $\left[F_{1}(1,14)=18.10, M S_{\mathrm{e}}=.007, p<.001 ; F_{2}(1,38)=\right.$ $\left.6.52, M S_{\mathrm{e}}=.027, p<.01\right]$. Fewer errors were made to targets from the associative-semantic rather than from the semantic-feature pairs ( $3 \%$ vs. $6 \%$, respectively).

\section{Discussion}

The results, again, show significant priming facilitation for both semantic-feature and associative-semantic prime-target pairs in the primed lexical decision task at a relatively long prime-target SOA. These results replicate those reported by McRae and Boisvert (1998) as concerns the semantic-feature pairs, and those of numerous studies as concerns associative priming (see Hutchison, 2003, for a review). Our results do not indicate that priming decreased specifically for the semantic-feature pairs in comparison with the results obtained at a shorter SOA, in Experiment 6. If anything, the effect of priming was numerically larger in the present experiment.

A final experiment was run to test yet another hypothesis about the mechanism behind semantic priming, that forwarded by Wentura (2000) as well as by Forster (2004).

\section{EXPERIMENT 8}

Wentura (2000) and Forster (2004) proposed an alternative mechanism to account for semantic priming; according to their proposal, in a categorization task the prime-target configuration is considered an implicit question, such as "Is $X$ a $Y$ ?" When the question is congruent (as on related trials, when the prime and target are members of the same semantic category), decision times are accelerated as compared with when the prime and target words do not compose a congruent pair. Wentura suggested that the valences of the prime and target words can also produce a congruent compound and accelerate decisions. Forster clearly states that the process of categorization can be driven by such "congruence effects." To test this hypothesis, we conducted a final experiment with our semantic-feature pairs. Unlike the materials in the prior seven experiments, in the present experiment the unrelated primes were replaced with words from the same semantic category as the target (e.g., "fennel-squash" in- 
stead of "stilt-squash"). In line with the congruency hypothesis, this manipulation should in fact annul the priming effects we previously obtained, since all of the test pairs - both related and unrelated - consist of congruent pairs. If significant priming effects are nonetheless observed, this facilitation clearly could not be ascribed to congruency effects.

\section{Method \\ Participants. Forty French students took part in the experiment, which lasted roughly $10 \mathrm{~min}$. \\ Materials and Design. The 20 semantic-feature pairs plus 80 fillers were used. However, the unrelated semantic primes used in all prior experiments were now replaced by nouns from the same se- mantic category as the target word, matched in frequency and length to related primes (see Appendix C). Two counterbalanced lists were prepared such that all targets were seen in both prime conditions but in only one condition per list. A given participant saw only one list. A single, 43-msec prime exposure was used (followed by a 14-msec backward mask). \\ Procedure. The task was semantic categorization.}

\section{Results}

A repeated measures ANOVA was performed on the mean RTs for correct answers between 300 and $1,000 \mathrm{msec}$ (this excluded $9 \%$ of the data overall) and on error rates, with participants and items as sources of variance, prime relatedness (related vs. unrelated) as a repeated measure, and list as a dummy variable. The results are summarized in Table 3.

The effect of prime was significant $\left[F_{1}(1,38)=8.24\right.$, $M S_{\mathrm{e}}=3,396.21, p<.006 ; F_{2}(1,19)=5.00, M S_{\mathrm{e}}=$ $2,367.76, p<.0375]$. Semantic categorization of the target words was faster when they were preceded by a semantically related rather than an unrelated prime (699 and $736 \mathrm{msec}$, respectively). The analysis of errors showed a slight trend toward an effect of prime relatedness by participants $\left[F_{1}(1,38)=3.83, M S_{\mathrm{e}}=1,838.5, p<.10\right.$; $\left.F_{2}<1\right]$. Slightly fewer errors occurred following unrelated as compared with related prime words $(7.75 \%$ and $10.75 \%$, respectively).

\section{Discussion}

These results invalidate the congruency hypothesis developed by Wentura (2000) and Forster (2004). Indeed, a robust and significant priming effect was observed for related semantic-feature pairs, even though the unrelated pairs were congruent - that is, the prime and target were from the same semantic category. Despite the attractiveness of the congruency hypothesis, it cannot account for the priming facilitation reported here. Moreover, this last demonstration replicates our previous results of automatic semantic priming under brief, masked conditions of prime presentation.

\section{GENERAL DISCUSSION}

The present study set out to determine the onset and evolution of priming as a function of the relationship between the prime and target words, on the one hand, and task demands, on the other. The results, obtained across eight
Table 3

Experiment 8: Mean Semantic Categorization Times (in Milliseconds), Standard Deviations, and Error Rates to Target Words, As Functions of Prime Relatedness (Prime Duration, 43 msec)

\begin{tabular}{crrr}
\hline & RT & $S D$ & \%E \\
\hline Related & 699 & 104 & 10.75 \\
Unrelated & 736 & 114 & 7.75 \\
Effect & 37 & & \\
\hline
\end{tabular}

experiments, are straightforward. Provided that the task mandates the retrieval of semantic information and that the prime and target words have strong semantic-feature overlap and perceived similarity, priming facilitation can be evidenced extremely early, as shown in our first experiment and replicated in the last. The onset of priming is delayed, however, when either the amount of feature overlap/semantic similarity between the prime and target decreases (Experiments 2-4) or the extent to which the task necessitates semantic processing is reduced (Experiments 5-7). These two topics will be examined in turn.

The question of the type of prime-target relationship that will produce automatic priming has been addressed in two recent reviews (Hutchison, 2003; Lucas, 2000), with differing conclusions. On the one hand, Lucas argued in her metareview that semantic priming without association is a robust phenomenon. She further concluded that the effect is not influenced by either strategic processing (as revealed by the comparison of different variants of the lexical decision task and/or of relatedness proportions) ${ }^{6}$ or SOA (above or below $250 \mathrm{msec}$ ). On the other hand, Hutchison argued rather strongly that reports of semantic priming, in particular for category coordinates, are marred by either the presence of an (albeit small, and sometimes reversed) associative relationship or the possibility of engaging in strategic processing. Our results, which show priming independent of SOA for category coordinates selected on the basis of high semantic similarity, coupled with the absence of facilitation at short SOAs for category coordinates that lacked semantic similarity but were associatively related (much more associatively related, it should be added, than the pairs that had high semantic-feature overlap), belie Hutchison's conclusions. Quite simply, added associative strength did not outweigh semantic similarity at short prime exposures in our study. Hence, in line with Lucas's conclusions, our results add to the existing evidence that semantic priming does not depend on association strength (even if it may be impossible to ever truly disentangle the two) and can be obtained in automatic conditions (Hines et al., 1986; Lund et al., 1995; Lund et al., 1996; McRae \& Boisvert, 1998; Perea \& Gotor, 1997; Perea \& Rosa, 2002; Thompson-Schill et al., 1998; Williams, 1996). Our finding that priming is evidenced earlier for semantic-feature than for associative-semantic pairs also extends the finding of McRae and Boisvert that priming was obtained at "short" SOAs $(250 \mathrm{msec})$ only when the prime and target had high degrees of semantic similarity and feature overlap. Finally, our results provide no support for the "associative boost" hypothesis: Greater priming was found 
for our category coordinate pairs with greater associative strength only at longer SOAs $(250 \mathrm{msec})$ and only in the lexical decision task. The issue of task demands is indeed our next topic.

How task demands impact on semantic priming has also been given considerable attention in the past (Balota \& Chumbley, 1984; Balota \& Paul, 1996; Becker et al., 1997; de Groot, 1990; Grainger \& Frenck-Mestre, 1998; Joordens \& Becker, 1997; Williams, 1996). The results we obtained at short prime exposures showed clear effects of task demands. The same materials that produced reliable semantic priming in a semantic categorization task at short prime-target SOAs (Experiments 1 and 8) failed to produce even a trend when the task was primed lexical decision (Experiment 5). This is not to say that the primed lexical decision task does not provide a tool for examining the structure of the lexicon. Priming facilitation was observed in the lexical decision task for our materials under conditions in which the prime was visible (Experiments 6 and 7), and there is ample evidence in the literature that this task is effective. However, as revealed by a comparison of the results of Experiments 1-7, lexical decisions are not as sensitive to early semantic processing as is semantic categorization. To illustrate further, had we used only primed lexical decision, we would have concluded that semantic priming was not obtained below $50 \mathrm{msec}$ of prime presentation, akin to Perea and Rosa's (2002) conclusion from their own results (but see Hines et al., 1986). By using a semantic categorization task, however, we were able to evidence semantic priming much earlier for category coordinates that enjoyed high semantic similarity and feature overlap. The same effect of task demands on semantic priming was reported by Grainger and Frenck-Mestre, but with different materials and bilingual participants. Greenwald, Draine, and Abrams (1996) also provided evidence of priming facilitation in a categorization task at extremely short prime exposures, but for response accuracy rather than RTs. Becker et al. published complementary results, showing that semantic priming withstands lags of several items between the prime and the target word in a semantic task, but not in lexical decision. Our results concur with the general conclusion that lexical decision is less suited than a task that necessitates the retrieval of semantic information for the study of how semantic relationships are stored in the lexicon and affect processing.

Interestingly, the two most recent reviews of semantic priming excluded the results of studies that used semantic categorization (Hutchison, 2003; Lucas, 2000), on the premise that this task is strategy dependent. Our results clearly show that this is not necessarily the case. First, the results of our study prove fatal to the congruency hypothesis (Forster, 2004; Wentura, 2000); we obtained facilitation for category coordinate pairs that were rated as highly semantically similar, independent of whether unrelated pairs were category coordinates or not (see Experiments 1, 3,4 , and 8 ). Hence, facilitated responses to the target were not (or not solely) determined by the response congruency of the prime and target words. Second, our results also demonstrate that the facilitation we observed in the categorization task is not attributable to the prime's or the target's being a highly typical member of its category. ${ }^{7}$ In fact, priming was found earlier in our study for category coordinates that had high semantic similarity but that were often not typical members of their semantic category, as compared with pairs that had less semantic overlap but slightly higher typicality ratings. ${ }^{8}$ As such, the typicality of members does not appear to have played an important role (see Neely, 1991, for a discussion of this issue), nor could it have allowed participants to predict targets.

The present experiments revealed facilitated target processing under conditions in which participants did not report seeing the preceding prime word and (assumedly) did not consciously identify it on the majority of trials. The issue of "unconscious" or "subliminal" priming has been the source of considerable debate (for discussions, see Dark, 1988; Debner \& Jacoby, 1994; Hirshman \& Durante, 1992), and it is not our intention here to specifically address this issue. What is important for the present study is the fact that the onset of priming differed as a function of both task and prime-target relationship, not whether the participants could report the prime. Nonetheless, for the sake of comparison with previous studies, we ran an independent posttest aimed at determining prime visibility. All 40 prime-target pairs were presented to 40 participants under the same conditions as in Experiments 1 and 2. However, the task was to ignore the target word and to try to identify the preceding prime. The results revealed that fewer than $2 \%$ of primes could be identified when they were presented for $28 \mathrm{msec}$ and forward and backward masked. When the prime was presented for $43 \mathrm{msec}$, again with forward and backward masks, prime reportability in the posttest was still only $27 \%$. Thus, it seems safe to conclude that in the semantic categorization task, in which attention was directed to the target words and participants were not informed of the presence of a preceding prime, primes were generally not identified by participants, and undoubtedly were not strategically used to predict the target words.

As outlined in the introduction, the present experiments were designed with recent models of semantic processing in mind. The pattern of results we obtained is in line with HAL (Lund \& Burgess, 1996), as well as with the distributed models promoted by Masson (1995), McRae et al. (1997), and Plaut (1995; Plaut \& Booth, 2000). These models all predict that priming should strengthen as a function of semantic processing and overlap. Indeed, our results show that priming is found earlier if (1) the task demands the retrieval of semantic information and (2) the prime-target pairs bear strong semantic similarity. At longer delays, less similar pairs, such as the associative-semantic pairs we employed, produce facilitation, again in line with previous results (Cree et al., 1999; McRae \& Boisvert, 1998). Note, however, that our results are not entirely consistent with Plaut's simulations. Although, like Plaut, we found quite different patterns of priming onset for associative and semantic relationships, we did not replicate his finding of a rapid decay of facilitation for semantic pairs; instead, our results show significant priming for these pairs even at the longest prime duration. Nonetheless, it should be noted that Plaut trained his model with a different set of materials 
than ours, and that his were modeled less closely on human perception of semantic similarity.

Perhaps the most controversial result of the present study is that it belies the importance of associative relatedness in producing priming. The key, undoubtedly, lies in the task demands. Joordens and Becker (1997) showed that even the lexical decision task can be manipulated so as to produce effects that are generally not observed. Here we found that, at very short prime exposures, associative relatedness between the prime and target words has less impact than semantic similarity, but our task - semantic categorization - was one that mandated semantic processing. As already stated, the seeming importance of associative relatedness in previous studies certainly relates directly to the task-lexical decision-used to explore the lexicon. An important caveat, nonetheless, is that our associative-semantic pairs were developed so as to be both associatively related and category coordinates, so in most cases their association strength was not equivalent to first, but rather to second, associates. It is possible that increasing the associative strength would produce an earlier onset of priming than we have found.

In conclusion, the present series of experiments provides solid evidence that semantic similarity produces facilitation extremely early, provided that one is probing for semantic processing. Moreover, the presence of an associative link does not generally enhance the effect of semantic similarity. The question for future research in semantic priming thus seems to be to define the concepts of semantic similarity and featural overlap. Only serious advances in this domain will better our understanding of the mechanisms behind semantic priming.

\section{AUTHOR NOTE}

Correspondence relating to this article may be sent to $\mathrm{S}$. Bueno, Université de Paris 13, UFR LSHS/UTRPP, EA 3413, 99 avenue Jean-Baptiste Clément, 93430 Villetaneuse, France (e-mail: bueno@univ-paris13.fr).

\section{REFERENCES}

Balota, D. A., \& Chumbley, J. I. (1984). Are lexical decisions a good measure of lexical access? The role of word frequency in the neglected decision stage. Journal of Experimental Psychology: Human Perception \& Performance, 10, 340-357.

Balota, D. A., \& Paul, S. T. (1996). Summation of activation: Evidence from multiple primes that converge and diverge within semantic memory. Journal of Experimental Psychology: Learning, Memory, \& Cognition, 22, 827-845.

Battig, W. F., \& Montague, W. E. (1969). Category norms for verbal items in 56 categories: A replication and extension of the Connecticut category norms. Journal of Experimental Psychology Monographs, 80(3, Pt. 2), 1-46.

Becker, S., Moscovitch, M., Behrmann, M., \& Joordens, S. (1997). Long-term semantic priming: A computational account and empirical evidence. Journal of Experimental Psychology: Learning, Memory, \& Cognition, 23, 1059-1082.

Bueno, S., \& Frenck-Mestre, C. (2002). Rapid activation of the lexicon: A further investigation with behavioral and computational results. Brain \& Language, 81, 120-130.

Burgess, C. (2000). Theory and operational definitions in computational memory models: A response to Glenberg and Robertson (2000). Journal of Memory \& Language, 43, 402-408.

Collins, A. M., \& LofTus, E. F. (1975). A spreading-activation theory of semantic processing. Psychological Review, 82, 407-428.

Content, A., Mousty, P., \& Radeau, M. (1990). BRULEX: Une base de données lexicales informatisée pour le français écrit et parlé. L'Année Psychologique, 90, 551-566.

Cree, G. S., McNorgan, C., \& McRae, K. (2006). Distinctive features hold a privileged status in the computation of word meaning: Implications for theories of semantic memory. Journal of Experimental Psychology: Learning, Memory, \& Cognition, 32, 643-658.

Cree, G. S., McRae, K., \& McNorgan, C. (1999). An attractor model of lexical conceptual processing: Simulating semantic priming. Cognitive Science, 23, 371-414.

DARK, V. J. (1988). Semantic priming, prime reportability, and retroactive priming are interdependent. Memory \& Cognition, 16, 299-308.

DeBner, J. A., \& JACOBY, L. L. (1994). Unconscious perception: Attention, awareness, and control. Journal of Experimental Psychology: Learning, Memory, \& Cognition, 20, 304-317.

DE Groot, A. M. B. (1990). The locus of the associative-priming effect in the mental lexicon. In D. A. Balota, G. B. Flores d'Arcais, \& K. Rayner (Eds.), Comprehension processes in reading (pp. 101-123). Hillsdale, NJ: Erlbaum.

DE Groot, A. M. B. (1992). Determinants of word translation. Journal of Experimental Psychology: Learning, Memory, \& Cognition, 18, 1001-1018.

Ferrand, L., \& Alario, F.-X. (1998). Normes d'associations verbales pour 366 noms d'objets concrets. L'Année Psychologique, 98, 659-709.

FORSTER, K. I. (2004). Category size effects revisited: Frequency and masked priming effects in semantic categorization. Brain \& Language, 90, 276-286.

Forster, K. I., \& DAVIS, C. (1984). Repetition priming and frequency attenuation in lexical access. Journal of Experimental Psychology: Learning, Memory, \& Cognition, 10, 680-698.

Forster, K. I., Mohan, K., \& Hector, J. (2003). The mechanics of masked priming. In S. Kinoshita \& S. J. Lupker (Eds.), Masked priming: State of the art (pp. 3-37). Hove, U.K.: Psychology Press.

Frenck-Mestre, C., \& Prince, P. (1997). Second language autonomy. Journal of Memory \& Language, 37, 481-501.

Glenberg, A. M., \& Robertson, D. A. (2000). Symbol grounding and meaning: A comparison of high-dimensional and embodied theories of meaning. Journal of Memory \& Language, 43, 379-401.

Grainger, J., \& FrencK-Mestre, C. (1998). Masked priming by translation equivalents in proficient bilinguals. Language \& Cognitive Processes, 13, 601-623.

Greenwald, A. G., Draine, S. C., \& Abrams, R. L. (1996). Three cognitive markers of unconscious semantic activation. Science, 273, 1699-1702.

Hines, D., Czerwinski, M., Sawyer, P. K., \& Dwyer, M. (1986). Automatic semantic priming: Effect of category exemplar level and word association level. Journal of Experimental Psychology: Human Perception \& Performance, 12, 370-379.

Hirshman, E., \& Durante, R. (1992). Prime identification and semantic priming. Journal of Experimental Psychology: Learning, Memory, \& Cognition, 18, 255-265.

Hodgson, J. M. (1991). Informational constraints on pre-lexical priming. Language \& Cognitive Processes, 6, 169-205.

Hutchison, K. A. (2003). Is semantic priming due to association strength or feature overlap? A microanalytic review. Psychonomic Bulletin \& Review, 10, 785-813.

Imbs, P., Martin, R., \& the Centre de Recherche pour un TréSOR DE la Langue FrançaISE (1971). Dictionnaire des fréquences. Paris: Didier.

JARED, D., \& SEIDENBERG, M. S. (1991). Does word identification proceed from spelling to sound to meaning? Journal of Experimental Psychology: General, 120, 358-394.

JoORdens, S., \& BECKER, S. (1997). The long and short of semantic priming effects in lexical decision. Journal of Experimental Psychology: Learning, Memory, \& Cognition, 23, 1083-1105.

Landauer, T. K., \& Dumais, S. T. (1997). A solution to Plato's problem: The latent semantic analysis theory of acquisition, induction, and representation of knowledge. Psychological Review, 104, 211-240.

LuCAS, M. (2000). Semantic priming without association: A metaanalytic review. Psychonomic Bulletin \& Review, 7, 618-630.

Lund, K., \& Burgess, C. (1996). Producing high-dimensional semantic spaces from lexical co-occurrence. Behavior Research Methods, Instruments, \& Computers, 28, 203-208. 
Lund, K., Burgess, C., \& Atchley, R. A. (1995). Semantic and associative priming in high-dimensional semantic space. In J. D. Moore \& J. F. Lehman (Eds.), Proceedings of the 17th Annual Conference of the Cognitive Science Society (pp. 660-665). Mahwah, NJ: Erlbaum.

Lund, K., Burgess, C., \& Audet, C. (1996). Dissociating semantic and associative word relationships using high-dimensional semantic space. In G. W. Cottrell (Ed.), Proceedings of the 18th Annual Conference of the Cognitive Science Society (pp. 603-608). Mahwah, NJ: Erlbaum.

LUPKER, S. J. (1984). Semantic priming without association: A second look. Journal of Verbal Learning \& Verbal Behavior, 23, 709-733.

Masson, M. E. J. (1995). A distributed memory model of semantic priming. Journal of Experimental Psychology: Learning, Memory, \& Cognition, 21, 3-23.

McKoon, G., \& RAtcLIfF, R. (1992). Spreading activation versus compound cue accounts of priming: Mediated priming revisited. Journal of Experimental Psychology: Learning, Memory, \& Cognition, 18, $1155-1172$.

McNamara, T. P. (1992). Priming and constraints it places on theories of memory and retrieval. Psychological Review, 99, 650-662.

McNamara, T. P., \& Altarriba, J. (1988). Depth of spreading activation revisited: Semantic mediated priming occurs in lexical decisions. Journal of Memory \& Language, 27, 545-559.

McRAE, K. (2004). Semantic memory: Some insights from featurebased connectionist attractor networks. In B. H. Ross (Ed.), The psychology of learning and motivation: Advances in research and theory (Vol. 45, pp. 41-86). San Diego: Academic Press.

McRAe, K., \& BoIsvert, S. (1998). Automatic semantic similarity priming. Journal of Experimental Psychology: Learning, Memory, \& Cognition, 24, 558-572.

McRae, K., Cree, G. S., Seidenberg, M. S., \& McNorgan, C. (2005). Semantic feature production norms for a large set of living and nonliving things. Behavior Research Methods, 37, 547-559.

McRae, K., Cree, G. S., Westmacott, R., \& de Sa, V. R. (1999). Further evidence for feature correlations in semantic memory. Canadian Journal of Experimental Psychology, 53, 360-373.

McRae, K., De Sa, V. R., \& SeidenberG, M. S. (1997). On the nature and scope of featural representations of word meaning. Journal of Experimental Psychology: General, 126, 99-130.

Meyer, D. E., Schvaneveldt, R. W., \& Ruddy, M. G. (1972, November). Activation of lexical memory. Paper presented at the 13th Annual Meeting of the Psychonomic Society, St. Louis, MO.

Meyer, D. E., Schvaneveldt, R. W., \& Ruddy, M. G. (1974). Functions of graphemic and phonemic codes in visual word-recognition. Memory \& Cognition, 2, 309-321.

Moss, H. E., Hare, M. L., Day, P., \& Tyler, L. K. (1994). A distributed memory model of the associative boost in semantic priming. Connection Science, 6, 413-427.

Moss, H. [E.], \& OLDER, L. (1996). Birkbeck word association norms. Hove, U.K.: Psychology Press.

Moss, H. E., Ostrin, R. K., Tyler, L. K., \& Marslen-Wilson, W. D (1995). Accessing different types of lexical semantic information: Evidence from priming. Journal of Experimental Psychology: Learning, Memory, \& Cognition, 21, 863-883.

NeELY, J. H. (1991). Semantic priming effects in visual word recognition: A selective review of current findings and theories. In D. Besner \& G. W. Humphreys (Eds.), Basic processes in reading: Visual word recognition (pp. 264-336). Hillsdale, NJ: Erlbaum.

NeEly, J. H., \& KaHAN, T. A. (2001). Is semantic activation automatic? A critical re-evaluation. In H. L. Roediger III, J. S. Nairne, I. Neath, \& A. M. Surprenant (Eds.), The nature of remembering: Essays in honor of Robert C. Crowder (pp. 69-93). Washington, DC: American Psychological Association.

New, B., Pallier, C., Ferrand, L., \& Matos, R. (2001). Une base de données lexicales du français contemporain sur Internet: LEXIQUE. L'Année Psychologique, 101, 447-462.

Perea, M., \& Gotor, A. (1997). Associative and semantic priming effects occur at very short stimulus-onset asynchronies in lexical decision and naming. Cognition, 62, 223-240.

Perea, M., \& Rosa, E. (2002). The effects of associative and semantic priming in the lexical decision task. Psychological Research, 66, 180-194.
Plaut, D. C. (1995). Semantic and associative priming in a distributed attractor network. In J. D. Moore \& J. F. Lehman (Eds.), Proceedings of the 17th Annual Conference of the Cognitive Science Society (pp. 37-42). Mahwah, NJ: Erlbaum.

Plaut, D. C., \& Bоотн, J. R. (2000). Individual and developmental differences in semantic priming: Empirical and computational support for a single-mechanism account of lexical processing. Psychological Review, 107, 786-823.

Plaut, D. C., \& Booth, J. R. (2006). More modeling but still no stages: Reply to Borowsky and Besner. Psychological Review, 113, 196-200.

Randall, B., Moss, H. E., Rodd, J. M., Greer, M., \& Tyler, L. K. (2004). Distinctiveness and correlation in conceptual structure: Behavioral and computational studies. Journal of Experimental Psychology: Learning, Memory, \& Cognition, 30, 393-406.

Ratcliff, R., \& McKoon, G. (1988). A retrieval theory of priming in memory. Psychological Review, 95, 385-408.

Seidenberg, M. S., Waters, G. S., SAnders, M., \& Langer, P. (1984). Pre- and postlexical loci of contextual effects on word recognition. Memory \& Cognition, 12, 315-328.

Shelton, J. R., \& Martin, R. C. (1992). How semantic is automatic semantic priming? Journal of Experimental Psychology: Learning, Memory, \& Cognition, 18, 1191-1210.

SPENCE, D. P., \& Owens, K. C. (1990). Lexical co-occurrence and association strength. Journal of Psycholinguistic Research, 19, 317-330.

Thompson-Schill, S. L., KurTZ, K. J., \& Gabrieli, J. D. E. (1998) Effects of semantic and associative relatedness on automatic priming. Journal of Memory \& Language, 38, 440-458.

Tourette, G. (1979). Table catégorielles: Normes de production dans 30 catégories sémantiques. Poitiers, France: Université de Poitiers, Laboratoire de Psychologie.

VAn Overschelde, J. P., Rawson, K. A., \& Dunlosky, J. (2004). Category norms: An updated and expanded version of the Battig and Montague (1969) norms. Journal of Memory \& Language, 50, 289-335.

Wentura, D. (2000). Dissociative affective and associative priming effects in the lexical decision task: Yes versus no responses to word targets reveal evaluative judgment tendencies. Journal of Experimental Psychology: Learning, Memory, \& Cognition, 26, 456-469.

WiLliams, J. N. (1994). The relationship between word meanings in the first and second language: Evidence for a common, but restricted, semantic code. European Journal of Cognitive Psychology, 6, 195-220.

WiLLIAMS, J. N. (1996). Is automatic priming semantic? European Journal of Cognitive Psychology, 8, 113-161.

\section{NOTES}

1. Most recently, work along this line has expanded, to investigate the role of distinctive features as well as of feature correlations in the semantic representation of concepts (Cree, McNorgan, \& McRae, 2006; McRae et al., 1999; but see Randall, Moss, Rodd, Greer, \& Tyler, 2004).

2. One could make the critique that the results we report here were obtained under conditions that facilitated the evidencing of priming, since each target was seen repeatedly and in all prime conditions by each participant. Although strategic processing is not a likely candidate to explain our data, because a postcheck showed very low prime reporting, repeated presentation of a target could still have facilitated its processing, thereby leaving more resources for prime processing. To counter this argument, we ran two further control studies. In both, the same critical semantic-feature and filler pairs were used as in Experiment 1, but no repetition trials were presented. In each of the studies, a single prime duration was used.

The results of the first control, which involved 24 participants in a between-participants design in which the targets were seen only once by a participant, showed significant priming facilitation at a $43-\mathrm{msec}$ (forward and backward) masked prime duration $\left[F_{1}(1,22)=8.23, M S_{\mathrm{e}}=\right.$ $\left.1,283.37, p<.01 ; F_{2}(1,19)=7.89, M S_{\mathrm{e}}=1,529, p<.01\right]$. Semantic categorization times were faster on related $(629 \mathrm{msec})$ than on unrelated $(659 \mathrm{msec})$ trials. The analysis of errors showed a trend toward an effect of prime relatedness $\left[F_{1}(1,22)=3.22, p<.09 ; F_{2}(1,19)=4.12, p<\right.$ $.10]$, because slightly fewer semantic classification errors followed a related than an unrelated prime word ( $3.9 \%$ vs. $6.25 \%$, respectively). Moreover, a posttest performed with the same participants revealed very low prime reporting $(4.5 \%)$, excluding the possibility that the results were due to strategic use of the prime. 
However, the results of the second control, which involved another 24 participants in a within-subjects design, in which participants saw each prime once and each target twice (once in each prime condition) at a $28-\mathrm{msec}$ (forward and backward) masked prime duration, did not replicate our findings. Semantic categorization times were numerically slightly faster on related $(619 \mathrm{msec})$ than on unrelated $(626 \mathrm{msec})$ trials, but this difference was not statistically reliable $\left[F_{1}(1,23)=1.23, M S_{\mathrm{e}}=\right.$ 386.86 , n.s.; $F_{2}(1,19)=1.51, M S_{\mathrm{e}}=466.90$, n.s.]. The analysis of errors showed a trend toward an effect of prime relatedness $\left[F_{1}(1,23)=3.22\right.$, $\left.p<.09 ; F_{2}(1,19)=3.97, p<.06\right]$, because slightly fewer semantic classification errors followed a related than an unrelated prime word ( $4 \%$ vs. $6.25 \%$, respectively)

The combined results of these independent controls of our first experiment show that the semantic facilitation we reported at $43 \mathrm{msec}$ of masked priming is robust and replicable, and not dependent on multiple presentations of the prime and/or the target. At extremely brief prime presentations, however - that is, at $28 \mathrm{msec}$ - our results indicate that although priming can be obtained, as shown by Experiment 1 and other studies (Grainger \& Frenck-Mestre, 1998), the effect is apparently linked to the experimental design. Perea and Gotor (1997) have also shown that priming at very brief SOAs is limited in scope.

3. As a further comparison, an ANOVA was performed on the item means for the associative-semantic pairs from the present experiment and the semantic-feature pairs from Experiment 1. A significant interaction emerged between prime type (semantic-feature vs. associative-semantic) and prime relatedness (related vs. unrelated) $\left[F_{2}(1,38)=10.61, M S_{\mathrm{e}}=\right.$ $580.55, p<.005]$. Post hoc comparisons (Tukey HSD) confirmed significant facilitation for the semantic-feature pairs (21-msec effect, $p<$ $.002)$, whereas no priming was found for the associative-semantic pairs (-4-msec effect, n.s.)

4. A posttest was performed to test for the visibility of the prime words. Materials were presented as in the main experiment, but participants were requested to ignore the target and try to identify the word preceding it - that is, the prime. Prime reportability was high overall (78\%). It was greater for primes related to the target than for those not related $[85 \% \mathrm{vs}$. $\left.70 \% ; F_{1}(1,12)=12.01, M S_{\mathrm{e}}=2.56, p<.005\right]$ and for primes that were associated with the target rather than related by virtue of shared semantic features [ $82 \%$ vs. $\left.74 \% ; F_{1}(1,12)=4.82, M S_{\mathrm{e}}=1.93, p<.05\right]$.

5. An ANOVA was performed on the item means across Experiments $1-4$. For the semantic-feature pairs, we obtained main effects of prime relatedness $\left[F_{2}(1,19)=43.81, M S_{\mathrm{e}}=740.01, p<.001\right]$ and prime duration $\left[F_{2}(1,57)=15.33, M S_{\mathrm{e}}=2,592.95, p<.001\right]$, with no reliable interaction effect $\left[F_{2}(1,57)=1.97, M S_{\mathrm{e}}=1,130.50, p<.1\right]$. Thus, although the effect of priming grew numerically across experiments with increasing prime duration, the effects at long and the shorter prime durations were not statistically distinguishable. For the associative-semantic pairs, prime relatedness produced a trend $\left[F_{2}(1,19)=3.10, M S_{\mathrm{e}}=\right.$ $352.52, p<.09]$ that was modified by prime duration $\left[F_{2}(1,19)=8.62\right.$, $\left.M S_{\mathrm{e}}=289.18, p<.01\right]$, due to reliable priming for these pairs at longer prime exposures $\left[F_{2}(1,19)=12.83, M S_{\mathrm{e}}=536.52, p<.002\right]$ but not at brief ones $(F<1)$.

6. Note that response speed did have a significant impact on priming, since fast responses basically annulled priming facilitation.

7. McRae and Boisvert (1998) chose to use a concreteness task, rather than semantic categorization, given that the semantic-feature pairs they developed were often not typical members of their categories. Our results, obtained with a subset of their materials translated into French, suggest that this was an unnecessary precaution.

8. This result also provides further evidence that priming for category coordinates does not proceed via a common "category node," in line with several studies that have demonstrated that simply being category coordinates is not sufficient to produce priming (Cree et al., 1999; Lund et al., 1995; McRae \& Boisvert, 1998; Moss et al., 1995; Williams, 1996). As a general rule, priming is observed for category coordinates only when they have high semantic similarity (but see Williams, 1996, Experiment 4).

APPENDIX A

Experiments 2-7: The 20 Associative-Semantic Pairs by Semantic Category, With English Translations

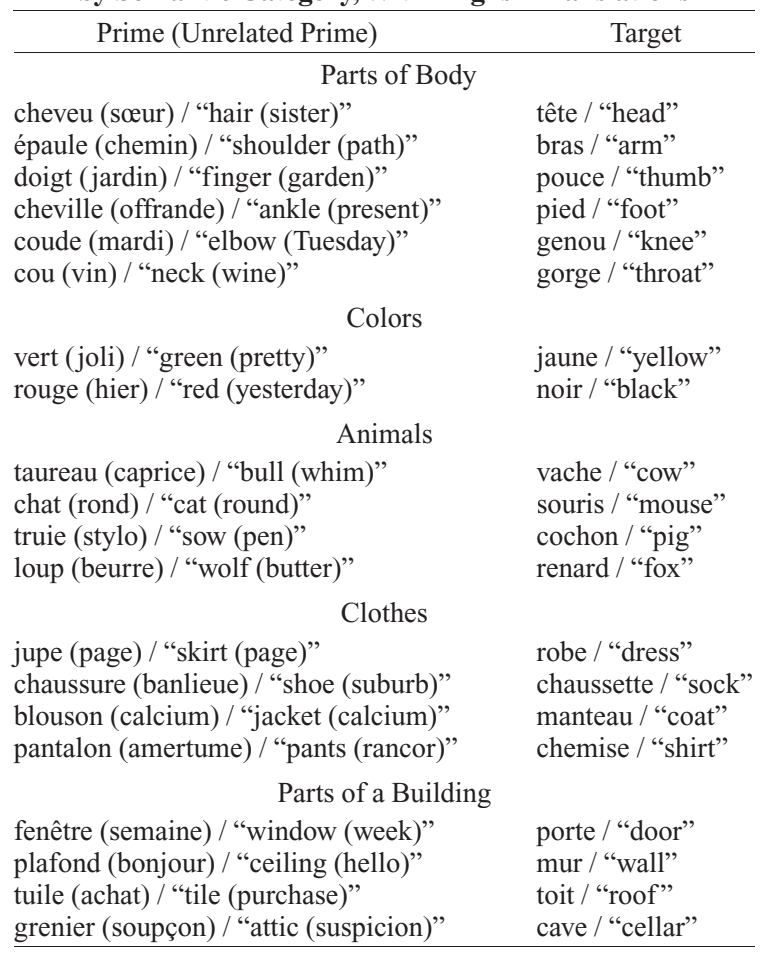




\section{APPENDIX B}

Experiments 1 and 3-7: The 20 Semantic-Feature Pairs by Semantic Category, With English Translations

Prime (Unrelated Prime)

dauphin (enclume) / "dolphin (anvil)" oie (arc) / "goose (bow)"

aigle (délai) / "eagle (time)"

élan (dôme) / "moose (dome)"

Clothes

chausson (aéroport) / "slipper (airport)" cravate (buisson) / "tie (bush)"

Vegetables

radis (cible) / "radish (target)"

potiron (échasse) / "pumpkin (stilt)" Target

\section{Means of Transportation}

moto (idem) / "motorcycle (same)" yacht (bémol) / "yacht (flat)"

wagon (époux) / "coach (partner)" camion (écorce) / "truck (bark)" autobus (divorce) / "bus (divorce)" canoe (loupe) / "canoe (magnifying glass)"

\section{Weapons}

hache (litre) / "axe (liter)" missile (chiffon) / "missile (rag)" couteau (dossier) / "knife (folder)" fusil (civil) / "rifle (citizen)" canon (union) / "cannon (matrimony)" épée (parc) / "sword (park)" baleine / "whale" dinde / "turkey" faucon/ "hawk" caribou / "caribou"

sandale / "sandal" ceinture / "belt"

betterave / "beet" courge / "squash"

scooter / "scooter" navire / "ship" chariot / "wagon" fourgon / "van" métro / "subway" radeau / "raft"

tomahawk / "tomahawk" bombe / "bomb" poignard / "dagger" pistolet / "pistol" bazooka / "bazooka" lance / "spear" 


\section{APPENDIX C}

Experiment 8: The 20 Congruent Semantic-Feature Pairs by Semantic Category, With English Translations

\begin{tabular}{|c|c|}
\hline Prime (Unrelated Congruent Prime) & Target \\
\hline \multicolumn{2}{|l|}{ Animals } \\
\hline $\begin{array}{l}\text { dauphin (moineau) / "dolphin (sparrow)" } \\
\text { oie (rat) / "goose (rat)" } \\
\text { aigle (lapin) / "eagle (rabbit)" } \\
\text { élan (paon) / "moose (peacock)" }\end{array}$ & $\begin{array}{l}\text { baleine / "whale" } \\
\text { dinde / "turkey" } \\
\text { faucon / "hawk" } \\
\text { caribou / "caribou" }\end{array}$ \\
\hline \multicolumn{2}{|l|}{ Clothes } \\
\hline $\begin{array}{l}\text { chausson (gabardine) / "slipper (gabardine)" } \\
\text { cravate (culotte) / "tie (knickers)" }\end{array}$ & $\begin{array}{l}\text { sandale / "sandal" } \\
\text { ceinture / "belt" }\end{array}$ \\
\hline \multicolumn{2}{|l|}{ Vegetables } \\
\hline $\begin{array}{l}\text { radis (navet) / "radish (turnip)" } \\
\text { potiron (fenouil) / "pumpkin (fennel)" }\end{array}$ & $\begin{array}{l}\text { betterave / "beet" } \\
\text { courge / "squash" }\end{array}$ \\
\hline \multicolumn{2}{|c|}{ Means of Transportation } \\
\hline $\begin{array}{l}\text { moto (luge) / "motorcycle (luge)" } \\
\text { yacht (jeep) / "yacht (jeep)" } \\
\text { wagon (taxi) / "coach (taxi)" } \\
\text { camion (barque) / "truck (bark)" } \\
\text { autobus (charrue) / "bus (plough)" } \\
\text { canoë (fusée) / "canoe (skyrocket)" }\end{array}$ & $\begin{array}{l}\text { scooter / "scooter" } \\
\text { navire / "ship" } \\
\text { chariot / "wagon" } \\
\text { fourgon / "van" } \\
\text { métro / "subway" } \\
\text { radeau / "raft" }\end{array}$ \\
\hline \multicolumn{2}{|l|}{ Weapons } \\
\hline $\begin{array}{l}\text { hache (canif) / "axe (pocketknife)" } \\
\text { missile (flèche) / "missile (arrow)" } \\
\text { couteau (grenade) / "knife (grenade)" } \\
\text { fusil (sabre) / "rifle (saber)" } \\
\text { canon (fouet) / "cannon (whip)" } \\
\text { épée (obus) / "sword (shell)" }\end{array}$ & $\begin{array}{l}\text { tomahawk / "tomahawk" } \\
\text { bombe / "bomb" } \\
\text { poignard / "dagger" } \\
\text { pistolet / "gun" } \\
\text { bazooka / "bazooka" } \\
\text { lance / "spear" }\end{array}$ \\
\hline
\end{tabular}

(Manuscript received March 20, 2007;

revision accepted for publication December 4, 2007.) 